\title{
Vorwort zur dritten Auflage
}

Qeit dem ersten Erscheinen des Buches sind übor zwanzig Jahre verflossen. Ein Blick in das damals geschriebene Vorwort zeigt, daß die Fragen dieselben geblieben sind, daB sie sich im Lauf der Jahrzehnte eher verschärft als gemildert haben; sie sind dringender geworden als je. Die neue Bearbeitung aber wird auch zeigen, daB meine prinzipielle Stellung zu ihnen sich nicht verändert hat; hoffentlich wird sie zugleich Fortschritte in ihrer Behandlung zeigen, Fortschritte sowohl in der Richtung eines einfacheren und flüssigeren Stils, Fortschritte auch in der Richtung einer engeren Beziehung zum Leben der Gegenwart. Zu diesem Zwecke ist der SchluBteil vollständig neu gestaltet worden, er hofft in dieser Gestalt darzutun, daß die Grundgedanken des Buches keineswegs zeitfremd sind, daB sie vielmehr eben der Lage der Gegenwart manche Anregung bringen können.

Jena, im Januar 1918.

Rudolf Eucken 